\title{
Teacher Selection in the Public Sector: Challenges, Pitfalls and Opportunities
}

\author{
Chita Kasonde \& Ferdinand M. Chipindi \\ University of Zambia
}

\begin{abstract}
Studies by various scholars have revealed that in addition to formal qualifications, effective teachers possess a certain set of skills, characteristics, values and beliefs. However, there exists a gap in literature to determine how these qualities can be identified during the teacher selection process. This study was undertaken to identify the challenges and pitfalls that arise teacher selection based on paper evidence. The study aimed at building on existing literature by identifying opportunities for improving teacher selection by exploring tools that can best identify qualities of effective teachers. The focus was teacher selection in the Ministry of General Education. A qualitative method of investigation was employed and utilised interview guides to get in-depth insight into the challenges faced when conducting teacher selection. The study revealed that the current teacher selection process is not adequate in identifying the qualities effective teachers should possess. Despite these challenges and the inadequacy of the current teacher selection process, opportunities exist for improving teacher such as the use of aptitude tests and interviews in addition to the existing use of paper evidence. From this study it was concluded that not much emphasis is attached to selecting effective teachers because teacher selection is viewed more as being necessary in filling vacancies without realising the impact that teachers have on student performance. The study recommends increased funding for building capacities to incorporate selection tools such as aptitude tests and interviews, greater coordination between the MoGE and the TSC in providing teacher statistics to ensure that teacher recruitment advertisements clearly specify the teachers that are required as well as coordination between the TSC and teacher training institutions to address the mismatch between teacher supply and demand.
\end{abstract}

Key Terms: Teacher selection, effective teachers, qualities of effective teachers

\section{INTRODUCTION}

$\mathrm{D}$ uring the 2018 teacher recruitment exercise conducted in Zambia, over 27000 applications were received. Out of these, only 2000 teachers were selected. Given the large number of applications received, many of which were from teachers who possess the same qualifications, what guarantee is there that the selected candidates were the best? Was the selection process able to adequately address the concerns about transparency that many stakeholders had expressed during previous selection exercises? Linked to this is whether the selection process employed was able to discriminate amongst the candidates objectively and whether the 2000 selected teachers possessed the aptitudes and attitudes required to impart the right knowledge and values in the students given the diverse roles teachers play.
These concerns arise because the selection is a process that aims at choosing only high-quality, highly qualified employees from a pool of applicants that meet the desired requirements (Mondy, 2008). The procedures involved in selecting the right employees who are capable of performing to the expected standards of the organisation require a significant amount of time and financial resources. In the case of the nationwide selection of teachers, for example, this exercise can be too tedious and time consuming given the scale of applications received at the national level. The activity requires extensive screening to ensure that only the top applicants are picked. It also becomes necessary to consider a wide range of factors as this protects against adverse consequences that may arise from poorly selected teachers such as low student performance.

\subsection{Statement of the Problem}

As more applicants possessing qualifications in non-technical subjects chase few jobs, it becomes imperative that those who are selected are the cream of the crop. The problem, therefore, is that the current selection process that is based solely on paper evidence may not be adequate in ensuring that out of the thousands of applications received only the candidates likely to be effective teachers are selected. The selection process employed may not necessarily be the most objective in narrowing down the selection to the required numbers. Selecting teachers based on qualifications alone without taking into consideration the qualities that account for teacher effectiveness may result in effective teachers not being selected. Selecting teachers who are highly qualified and yet may not be effective teachers may result in a decline in the standard of education in the country.

\subsection{Research Objectives}

Given the scale of applications received in relation to the available jobs, the general aim of this research is to understand the challenges, pitfalls and opportunities arising from the mass recruitment of teachers in the public service.

The specific objectives are as follows:

1. To ascertain why teachers are selected on the basis of qualifications only.

2. To investigate whether any challenges have been encountered during the selection process.

3. To determine quality indicators of effective teachers as perceived by policy makers 
4. To identify opportunities for incorporating qualities of effective teachers in the selection process.

\section{3. $\quad$ Significance of the Study}

It is hoped that this study will offer insights into the challenges that may be faced in determining the right candidates for the available jobs in light of teacher applicants far exceeding the available job openings during the national teacher recruitment exercise. It may also highlight the possibilities of improving how teachers are selected by recommending more comprehensive and objective ways.

\section{LITERATURE REVIEW}

In this section, we review relevant literature to gain understanding on teacher recruitment and selection as well as its importance followed by gaining an understanding of the quality indicators of effective teachers. We highlight the present evidence on why selecting teachers on the basis of academic and professional qualifications alone may not be adequate in ensuring that the right choices regarding which candidates will contribute positively to the learner and the education sector as a whole.

Despite vast evidence linking teacher quality to student performance (Darling-Hammond, 1997), very little research has been conducted on teacher selection (Liu \& MooreJackson, 2003, Peterson, 2002). According to Stronge and Hindman (2006), research shows that there is a link between teacher quality and teacher selection. It follows therefore, that effective teachers cannot be hired without first understanding the qualities of effective teachers. In order to ensure that the right teachers are deployed in government schools, there is need to focus on two important areas and these are: identifying the qualities of effective teachers and linking these qualities to selection tools that are useful in identifying these qualities.

Selection as a process includes different steps which help the employer get to know the candidate better, his or her abilities, motivation, background and any other information which will be used in deciding whether the candidate is the right fit for the school. The initial screening process involves a review of application forms and references. This first step sets aside unsuitable applicants based on the criteria that is outlined in the job advertisements. Pratt (1987) noted that the rationale for screening candidates is in selecting sound policies regarding strategies for selecting candidates. In addition, it was noted that a sound policy is necessary in upholding the image of the hiring entity in the eyes of the profession to require the interviewers to reflect the criteria for quality teaching and for teaching potential and to demonstrate accountability on the part of the interviewers in searching for quality applicants and selecting them fairly. Upholding the image of the hiring entity is an important element during the teacher recruitment exercise owing to the fact the number of teaching positions available is far below those of the applicants. A rigorous screening policy improves transparency and confidence regarding those who are eventually deployed in the teaching service.

Despite studies showing the importance of teacher qualifications and their relationship to improved pupil performance (Chipindi and Chipindi, 2016; Thomas, SerenjeChipindi and Chipindi, 2020), studies conducted by DarlingHammond (2000) and Anderson (1991) strongly indicate that in addition to subject matter knowledge and teachers' qualifications, teachers' attitudes and teacher-student relationships are strong variables for improving student performance. Student performance is most often used as a yardstick for measuring teacher effectiveness. This ultimately leads to the question; how best can we select such effective teachers?

A variety of models for identifying effective teachers exist and these range from selection systems which are highly dependent on teachers' demonstrated mastery of subject matter as reflected in their performance on achievement tests, to evaluation systems that employ a broad range of criteria (Johnson \& Prom Jackson, 1986). One influential view of what makes teachers effective contends that the best teachers possess similar values about education such as commitment, persistence and being caring (Metzger and Wu, 2008). Beliefs, attitudes and values of teachers should be of particular importance to educational administrators if they are to hire effective teachers.

The appropriate selection tools to be used depends on how closely these tools can assess the variables directly related to the job and what inferences can be drawn on the candidate's future performance. The greater the ability to test the coverage of required knowledge, skills and abilities, the higher the predictability of a candidate's future job performance. The selection process typically involves the use of employment tests and comprehensive interviews (DeCenzo and Robbins, 2009). Of particular interest are cognitive and personality tests; and unstructured and structured interviews. Commercially available instruments that are specifically designed to aid the selection of effective teachers are Gallup's Teacher Perceiver Interview (TPI) and the Haberman Star Teacher selection interview. Over 2000 school districts in the United States of America have employed some type of commercially designed teacher interview to guide their selection decisions (Delli, 2001), with one of the most commonly used commercial teacher selection instruments being the Gallup Organisation's Teacher Perceiver Interview (TPI) (Metzger and Wu, 2008). In order for the MoGE to make the best decisions regarding deployment of teachers, there is need to consider a variety of selection tools that help to identify qualities of effective teachers and predict to a large extent the impact that such teachers will have on pupils.

Current research in Zambia (Kayungwa, 2002; Chipindi and Doyle, 2017 and Mutale, 2010) focuses on qualities of effective teachers without suggesting how these qualities can be identified during the selection process. The review of 
literature identified the most widely used teacher selection tools and strongly supports the need for the MoGE to improve the current teacher selection process in government schools to record improvement in the positive impact that teachers will have on lives of the pupils under their care. Whereas no selection tool can accurately predict how effective a teacher will be due to factors such as the school bureaucracy and atrisk learners, a combination of selection tools can improve these chances significantly. The need for a more intensive selection process is necessary in not only picking effective teachers but improving transparency of the process especially in light of the number of teachers seeking employment in the public sector.

\section{METHODOLOGY}

The purpose of the study was to find ways in which the selection process could be improved upon to include selection tools that have been found to be useful in identifying effective teachers. In this section, we focus on the methodology that was employed in achieving this purpose. We describe the study design, population, sample and sampling procedure, instruments used, data collection techniques as well as data analysis techniques. We end by describing the limitations of the study.

\subsection{Research Design}

The study was purely qualitative. This was deemed most appropriate because the study aimed at gaining a deeper understanding of the issues relating to teacher selection from the point of view of policy makers at the Teaching Service Commission who determine the selection criteria and the selection committees at district level who are involved in the selection process. The method helped to gain a deeper understanding on the complexities of teacher selection being conducted on such a large scale. This was done from the perspective of policy makers and policy implementers. The qualitative method also allowed us to gain in-depth understanding of the issues surrounding teacher selection by obtaining data on the values, opinions and experiences of those tasked with selecting and deploying teachers in government schools.

\subsection{Study Population}

Zambia consists of 10 provincial education offices and 105 district education offices that constitute the administration of Zambia (Central Statistical Office, 2018). All the provinces were represented and had teachers selected for deployment in each of these districts during the 2018 teacher recruitment exercise (Teaching Service Commission, 2018). The population of the study is therefore the entire provincial and district education offices that are responsible for the task of recruiting and selecting teachers.

\subsection{Study Sample}

The sample was picked from the eight (8) districts education offices in Lusaka province and the provincial education office.
Lusaka district was selected because it allowed the researcher to have access to both the policy makers at national level and implementers of the selection policy at district level Daka, Chipindi and Mkandawire, 2020). Additionally, a member of the Teaching Service Commission (TSC) was included in the research owing to the fact that one of the functions of the Commission is to regulate Human Resource Management in the Teaching Service. (Services Commission Act, 2016). The purposive sampling technique was used to select the respondents. Purposive sampling is the deliberate choice of a participant due to the qualities that he or she possesses (Ilker et al, 2016; Chipindi and Vavrus, 2018). This technique signifies that the researcher sees sampling as a series of strategic choices. Utilising this technique, a sample size of five (5) was decided upon; three (3) respondents from the District Education Board Secretary's office, one (1) from the provincial education office and one (1) from the TSC. Despite the small sample size, it was felt that this was representative owing to the positions that the respondents occupy as well as the role they play in the selection process.

\subsection{Research Instruments}

The researchers used a structured interview to collect data for the study. Kvale (1996) remarks that an interview is an interchange of views between two or more people on a topic of mutual interest. Chipindi (2018) similarly remarks that an interview is an inter-subjective exchange which provides insights into the interviewee's world. The researchers on the other hand were interested in determining whether the selection method that was being used at the time of conducting the research was sufficient in selecting effective teachers. Two types of interview were used to collect datathe interview guide and standardized open-ended interviews.

\subsection{Data analysis techniques}

Data was analysed qualitatively. In order to conduct the analysis, the data generated from the interviewee's responses was searched for common phrases and ideas which were then scrutinized to determine the emergence of themes. A summary of each interview was then written to incorporate the themes elicited from the data. A second but brief interview was conducted with each of the initial interviewees to check whether the first interview had been accurately and fully captured.

\subsection{Limitations}

The study was based on teacher selections conducted in Lusaka district and this meant that the findings could not be generalised to other districts. This is owing to factors such as the availability of teaching posts in relation to the applications received, subject specialisation and special education needs being sought in each district. 


\section{FINDINGS}

In this section we present the findings of our study on the challenges, opportunities and pitfalls of teacher selection in the Republic of Zambia.

\subsection{Challenges Encountered During the Selection Process}

Whereas Respondent 1 felt that no challenges are encountered during the selection process owing to the fact that process is part of their work and is conducted during normal working hours and within their workstations, the other four pointed out four major challenges that are encountered during the selection process.

\section{a) The Huge Volume of Application Relative to the Vacancies}

The first challenge that was mentioned by four of the five respondents and was cited as being the biggest challenge encountered was the number of applicants against the available vacancies. There are very few vacancies against a huge number of applicants, especially in Lusaka. One of the respondents felt the numbers were too small for people to even say that there was recruitment. One respondent stated: "If they say they are recruiting 2000 teachers in a particular year the number is shared amongst all the provinces and districts in the country. Some districts got as few as 20 positions which were divided into categories of Early Childhood Education, Primary and Secondary school". Respondent 2 clarified that no new vacancies were created during the 2018 teacher recruitment exercise and what was being done was merely filling of PMEC vacancies. "In 2018 no new vacancies were created. Only replacements were made for those that died or had retired... Vacancies are based on the vacancies identified on the district payroll. This has been the case for the past 3 or 4 years"

With the large number of applications comes the challenge of time taken to scrutinise the documents and sort them according to level of education attained, school teaching level i.e. ECE, primary and secondary; and subject specialisation. This meant that the selection committee had to work long hours to sort through all the applications in order to come up with the final numbers. Thus, according to one respondent, "This was a challenge because it meant that we had to work even at night to scrutinise the documents." Respondent 2 pointed out that while some applicants did not possess the required qualifications, the majority have good results. "...most are qualified, and selection becomes difficult."

Teacher selection on the basis of paper evidence is due to the challenges that are faced during the selection process. The findings revealed that the number of vacancies was not enough to warrant a rigorous selection process especially given the volume of applications received. The findings further revealed that in certain instances selection boils down to luck. Given these revelations and the findings of DarlingHammond (2000), the selection process may not necessarily result in effective teachers being selected as the criteria that is being used is not an objective way of coming up with the list of successful applicants. Using criteria such as intuition may result in effective teachers being denied the opportunity to positively contribute to the teaching profession. The implication of selecting teachers who are ineffective is the negative impact that this may have on student performance. Where policy makers are cognisant of the extent to which effective teachers affect student performance and where serious attempts are being made to improve student performance, greater emphasis would be placed in making sure that the selection process is structured in such a way that it increases the likelihood of selecting effective teachers.

\section{b) Nepotistic Pressures and Interference}

The second challenge that was pointed out by two of the respondents was to do with pressure - almost everyone wants to be recruited: "Everyone wants their relative to be picked." One of the respondents stressed the fact that in some instances there was interference from the local community and politicians: "Some would want to sneak in names of those who do not qualify." Another respondent added, "The names that are recommended are not always the names that appear on the list of deployed teachers. This seems to be the challenge relating to selection." To which he was quick to add, "...the changing of names is sometimes due to human error on the part of the selection committee that is only picked up at provincial level."

There is also pressure from teachers who are engaged at school level by Parent Teacher Committees having an expectation that when there is recruitment they will be automatically picked. "However, the challenge is that some of those teachers do not even meet the criteria set by the TSC. The point is to stick to the guidelines." Respondent 3 pointed out that the reason for the list of selected candidates being different from those that were published in print media is due to the fact that upon scrutiny of qualifications some qualifications are found to be fake. "In the final analysis those [teachers] that were selected did not appear in the newspaper, they were left out and substituted by others... factors such as scrutiny of qualifications is not done [at district level]." The desire for so many teachers to be employed in the public sector was identified as the biggest challenge: "The list of applicants will always be long, and some people will always be talking e.g. 10 slots from 1000 applicants. How do you select those? Of course, people will talk, no matter how transparent you will be, people will complain."

Whereas some of these preferred candidates meet the minimum requirements, others may not even be suitable for the position as determined by the selection committee. In the most extreme cases, the preferred candidates do not meet the requirements set by the TSC. There exists the need and moral obligation to select teachers in an objective manner. Selection should be based on merit and not on who has the most influence to guarantee their preferred applicant a job. It is imperative that teachers joining the teaching service are those who have passion and motivation for the job and not merely 
those who enter the profession because they want to be in employment. Issues to do with teachers having to be constantly monitored and performing below the expected standards can be avoided where teachers are selected on the basis of the positive beliefs and attitudes they have towards teaching.

Findings further revealed that there were instances where the names of teachers that were selected at district level were not always the names that were published in print media. Having a well-spelled out selection criteria would minimise or even do away with such occurrences. This is because a candidate would have gone through a two or three step screening process by different selection committees, that is, those screening applications, those conducting aptitude tests and the interview panel. However, it was revealed that another reason for the names selected at district level being different from those published as successful applicants is not always to do with nepotistic pressures as factors such as fake qualifications come into play. This raises the important question of how effective the current one step screening process is given that fake qualifications cannot be screened for before names are published.

\section{c) Specialised Subject Teacher Numbers}

The third challenge had to do with the subject specialisation of the teachers. Despite the 2018 teacher recruitment advert stating that preference would be given to teachers with professional qualifications in Natural Sciences, Mathematics, Design and Technology, Business Studies, ICT and Agricultural Sciences; the majority of the applicants had qualifications in civic education. Respondent 5 stressed the fact that recruitment of teachers is needs based. The MoGE through the DEBS office submits statistics on the teachers they need, and this is what the selection committee looks for. One respondent had this to say:

It is not a matter of just recruiting everyone but those who the schools need. I'll give you an example - if they need a teacher for Mathematics, what is the point of recruiting someone who has done civic education? And that has been a challenge because people go to colleges and universities according to what they want but not according to what the system wants.... The Ministry needs teachers in Science, Mathematics, Technology, and Business Studies. If you look at the numbers in these areas including Zambian language, we have very few. For French, we didn't even have any. So that in itself is a challenge.

Similarly, Respondent 3 highlighted the fact that the greatest need for teachers was in the areas of Mathematics and Science: "The demand is teachers of Science and Mathematics"

The challenge of supply of teachers not meeting the demands of the MoGE in terms of subject specialisation was attributed to the fact that the MoGE does not always provide statistics of the number of teachers that are needed in each subject on time. This results in the TSC placing advertisements without specifying the number of teachers needed for primary school and teachers in specific subjects for secondary schools. From the applications received, it has been observed that there are more teachers with qualifications in civic education and less in French, Mathematics, Sciences and Business Studies. The respondents point out that because of this, teachers who have qualifications in these specialist subject areas are in high demand but are relatively few.

It was felt that in this regard, the challenge is not so much that there are too many applicants but too many applicants to screen for the desired teaching areas such as Mathematics, Sciences and languages. Having information on the specific teachers that are required would assist in significantly reducing the applications received and make the process of screening applications less tedious. This is because only those teachers who qualify in terms of training in the required subject areas would be considered and this could be done in the first instance. For as long as the job adverts continue to be general in nature, the DEB office will continue to receive applications that will take away from the time that can be spent on conducting more in-depth screening of relevant applications. The volume of applications may even be manageable enough for aptitude tests and interviews to be conducted.

\subsection{Opportunities for Incorporating Qualities of Effective Teachers in the Selection Process}

Each of the participants was asked whether they felt there were any changes that needed to be made to the selection process in light of the challenges faced with the current selection process and also given the qualities of effective teachers that they had identified. The changes were in reference to the introduction of aptitude tests and face to face interviews.

Four of the respondents felt that can help in aiding selection decisions especially if administered effectively. Respondent 1 alluded to the fact that there has been informal mention on the introduction of aptitude tests: "There has been informal mention of the same. TSC has hinted especially after reports of non-performance by some teachers." Respondent 5 mentioned that the TSC is looking into the administrative issues surrounding the introduction of aptitude tests to reinforce the qualifications of teachers. He pointed out the following, "The beauty with aptitude tests is that there is no leakage - it's about you as an individual, you can repeat the same several times and still get the same average."

However, despite the respondents agreeing that the introduction of aptitude tests and interviews would help with the selection, it was felt that some teachers are very good at taking tests but are not good in class. Respondent 2 felt that despite the fact that interviews may be the best way of selecting teachers, she wondered about the time it would take going by the number of applications that were received during the 2018 recruitment exercise: "the fact that over 5000 
applications are received makes one wonder how long it may take to interview each one of them Even after shortlisting there are thousands of applications. The numbers are too big and will involve a lot of work." Respondent 3 equally felt that with mass recruitment, conducting interviews would take several days: "When there is mass recruitment, this can take many days.

Regarding any other changes to be made to the selection process, it was suggested by Respondent 3 the need for teachers who live in the rural areas to be given priority when they apply for work in the rural area over teachers coming from urban areas because they are used to that environment:

Most rural areas have trained teachers and if teachers are recruited from their respective areas the shortfall of teachers will be minimal rather than getting people from Kitwe and Lusaka to work in rural areas as they have not been able to stay in rural areas and have come back. From experience those brought up in say Lusaka and for the sake of the job are taken to Mkushi or Serenje, do not discharge their duties effectively because they are homesick. Eventually they wait for transfers to come back.

Finally, Respondent 4 felt that there is need for more funding: The government needs to pump in more money so that more teachers could be recruited for the rural areas and newly opened schools.

The general findings with regards the adequacy of the current teacher selection process was that it was not adequate in identifying the qualities of effective teachers owing to the fact that there is no interaction with the applicants. Selection decisions are based on paper evidence and this cannot be used to identify whether one is caring, passionate, motivated and hard working. Therefore, a more comprehensive selection criterion could be employed to select effective teachers. This is in line with the findings of Stronge and Hindman (2006) that show a strong link between teacher quality and teacher selection. In order to select effective teachers, it is necessary to first understand the qualities that such teachers possess. In the case of selection of teachers in the public sector, identifying the qualities of effective teachers will help come up with the right selection tools which will further assist in overcoming the challenge of narrowing down the number of applicants in a more objective manner.

The two selection tools that were identified as being most likely to be useful in selecting effective teachers were aptitude tests and interviews. These views support those of DeCenzo and Robbins (2009) who identified employment tests and comprehensive interviews as being part of the typical selection process. The use of aptitude tests would help to address the challenge of non-performing teachers. The introduction of aptitude tests would mean that only teachers who are able to demonstrate subject mastery necessary to perform their duties would be considered for teaching positions. In order to increase predictability of future performance, these aptitude tests would have to be structured in such a way that they cover the required knowledge, skills and abilities for one to effectively teach.

\section{CONCLUSIONS AND RECOMMENDATIONS}

It is therefore clear from the above analysis that the recruitment exercise of 2018 was merely conducted to replace teachers who had died, retired or had left the teaching service. The current selection process is inadequate in ensuring effective teachers are selected. The Teaching Service Commission agrees that the current selection criteria are inadequate as there is no way of determining whether a teacher will be effective in executing his/her duties. In terms of what opportunities are available for improving teacher selection it can be concluded that the incorporation of aptitude tests and interviews is a positive step in guaranteeing that effective teachers are selected as aptitude tests help to determine whether the applicant possesses the relevant knowledge whereas interviews help the selection committee to know whether he or she possesses the right attitudes, beliefs and values to be an effective teacher.

Based on these findings, our study concludes that there is a need to incorporate feedback from HODs and deputy head teachers as the direct supervisors of teachers on what qualities effective teachers possess. This feedback should in turn be incorporated in the selection process. We also recommend that all applicants should have their qualifications verified before submitting applications to avoid situations where after going through the selection process it is discovered that their results are not genuine. This would also reduce incidences of the published list of teachers being different from that submitted by the district selection committees.

The recruitment adverts also need to be very specific in terms of the number of teachers required in each district and in what areas of specialisation. This would reduce the number of applications being received for subject specialisations for which there exist no vacancies. This would mean that the selection committee has more time to scrutinise applications for factors that are relevant to teaching. It may also help to incorporate face to face interviews to determine whether teachers have the necessary set of beliefs, attitudes and traits of effective teachers. In addition to being knowledgeable, teachers ought to possess qualities that motivate learners and improve pupil performance. Finally, there is need for the selection process to be specific in identifying factors necessary for teachers to succeed in dealing with learners from different backgrounds. The process for selecting teachers to work in rural areas for example should address the challenges that those serving in rural areas face as well as the challenges that learners in these areas face.

On the whole, it can be concluded that there is not much emphasis attached to selecting effective teachers. Teacher selection is viewed more as an exercise that needs to be done in order to fulfil staffing needs without realising the importance of being intentional about the sort of teachers that make it into the teaching service. This is despite the fact that 
teachers are the most important resource that schools possess and given the role that they play in improving student performance. The fact that close to $90 \%$ of the education budget goes to emoluments of teachers and less than $4 \%$ goes to teaching and learning materials indicates the importance that is attached to human resources in schools. These factors should be reason enough for more time, effort and resources to be allocated to building capacities and putting in place modalities for incorporating aptitude tests and interviews in the selection process.

\section{REFERENCES}

[1] Anderson, L.W. (1991). Increasing Teacher Effectiveness. Paris: UNESCO

[2] Chipindi, F.M. (2018). Negotiating professional identities in a liberalized Sub-Saharan economy: A case of University of Zambia faculty (unpublished $\mathrm{PhD}$ dissertation). University of Minnesota, Minneapolis.

[3] Chipindi, F.M. \& Doyle, H. (2017). Zambia scoping study. In H. Doyle, A.M. Barrett \& A. Reeves (Eds.), Improving the quality of teaching in secondary education: scoping studies for Zambia, Malawi, Tanzania, Côte D'Ivoire and Senegal (pp. 4-32). Bristol: Bristol University.

[4] Chipindi, F.M. \& Chipindi, S.J. (2016). Trade-off issues in teacher education at the university of Zambia: Growing student numbers and the quality of teacher education processes. International Journal of Teaching and Learning in Africa 3(1), 82-86.

[5] Chipindi, F.M. \& Vavrus, F. (2018). The ontology of mention: Contexts, contests, and constructs of academic identity among the university of Zambia faculty. FIRE: Forum for International Research in Education, 4, (3), 102-116. ISSN: 2326-3873.

[6] Daka, H., Chipindi, F.M. \& Mwale-Mkandawire, M. (2020). The relationship between assessment practices and students' academic performances. A case of undergraduate students at the medical school of the university of Zambia, 2008 - 2016. Zambian Journal of Educational Management, Administration and Leadership, 1, (1), 143-156. ISSN: 2706-7416 (Print).

[7] Darling-Hammond, L. (1997). Doing what matters the most: Investing in quality teaching. National Commission on teaching and America's Future. Kutztown Distribution Center, Kutztown, PA.

[8] Darling-Hammond, L. (2000). Teacher Quality and Student Achievement: A Review of State Policy Evidence. Education
Policy Analysis Archives 8(1). ISSN 1068-2341. DOI: https://doi.org/10.14507/epaa.v8n1.2000

[9] DeCenzo, D.A., Robbins, S.P. (2009). Fundamentals of Human Resource Management. $10^{\text {th }}$ Edition. John Wiley \& Sons Inc.

[10] Delli, D. (2001). Criteria for adopting commercial interviews for teacher selections. The AASA Professor, 25(1), 30-33.

[11] Ilker, E., Musa, S.A., Alkassim, R.S. (2016). Comparison of Convenience Sampling and Purposive Sampling. American Journal of Theoretical and Applied Statistics, 5(1) DOI: 10.11648/j.ajtas.20160501.11

[12] Johnson, S.T., Prom-Jackson, S. (1986). The memorable teacher: Implications for teacher selection. Journal of Negro Education. 55(3), 272-283.

[13] Kayungwa, L.J. (2002). Qualities of an effective teacher as perceived by Grade 12 pupils and teachers in selected secondary schools in Lusaka. Masters dissertation. The University of Zambia.

[14] Kvale, S. (1996). Interview Views: An introduction to qualitative research interviewing. Thousand Oaks, CA. Sage Publications.

[15] Liu, E., Moore-Jackson, S. (2003). New Teachers' experiences of hiring: late, rushed and information poor. NGT working paper. Cambridge, MA: Project on the next Generation of teachers.

[16] Metzger, S., Wu, M. (2008). Commercial Teacher instruments: The validity of selecting teachers through beliefs, attitudes and values. Review of Educational Research. 78(4), 921-940.

[17] Mondy, R.W. (2008). Human Resource Management (10 $0^{\text {th }}$ ed.). New Jersey. Pearson Prentice Hall

[18] Mutale, H. (2010). School managers, teachers and pupils' opinions of effective teachers in selected high schools of Lusaka urban district. Masters dissertation. The University of Zambia.

[19] Peterson, K.D. (2002). Effective Teacher Hiring: A Guide to Getting the Best. Virginia. Association for Supervision and Curriculum Development (ASCD).

[20] Pratt, D. (1987). Predicting career success in teaching. Action in Teacher Education,7(4), 25-34.

[21] Stronge, J.H. (2002). Qualities of effective teachers. Alexandria, VA: Association for supervision and Curriculum Development.

[22] Stronge, J.H., Hindman, J.L. (2006). The teacher quality index. Alexandria, VA: Association for Supervision and Curriculum Development.

[23] Thomas, M. A.M., Serenje-Chipindi, J \& Chipindi, F.M. (2020), Comparing course syllabi from A to Z: Examining the contexts, content, and concerns for social foundations of education in Australia and Zambia. In A. E. Mazawi \& M. Stack (Eds.). Course Syllabi in Faculties of Education across the World: Bodies of Knowledge and their Discontents (pp 38-50). Sydney: Bloomsbury, ISBN 978-1-3500-9425-3 (hardback) 978-1-35009427-7 (online). 